\title{
Analysis of the control strategy of range extender system on the vehicle $\mathrm{NVH}$ performance
}

\author{
Jingchang Chen ${ }^{1}$, Xiangzhen Kong ${ }^{2}$, Peiran $\mathbf{L i}^{3}$ \\ ${ }^{1,3}$ State Key Laboratory of Vehicle NVH and Safety Technology, Chongqing, China \\ ${ }^{2}$ China Automotive Engineering Research Institute Co., Jinyu Street, No. 9, Chongqing, China \\ ${ }^{1}$ Corresponding author \\ E-mail: ${ }^{1}$ chenwzhangy@163.com, ${ }^{2}$ kongxiangzhen@caeri.com.cn, ${ }^{3}$ lipeiran@caeri.com.cn
}

Received 31 August 2020; received in revised form 28 September 2020; accepted 6 October 2020 DOI https://doi.org/10.21595/vp.2020.21681

Check for updates

Copyright $\left({ }^{\circ} 2020\right.$ Jingchang Chen, et al. This is an open access article distributed under the Creative Commons Attribution License, which permits unrestricted use, distribution, and reproduction in any medium, provided the original work is properly cited.

\begin{abstract}
With focus on NVH performance, this paper studies the range extender system control strategy such as the initial start speed, operating points, speed up and down control method between operating points of the range extender, etc. At the same time, the confirmation of the operating points of the range extender based on the full vehicle frequency distribution and vibration and noise level of key points (seat rail, driver's inner ear) was performed. Finally, we conducted objective test and compared the test data with benchmark vehicles.
\end{abstract}

Keywords: range extender, NVH, control strategy, sound package.

\section{Introduction}

New energy vehicles have become the development trend in the field of modern transportation. However, the driving range anxiety has become the key point of pure electric vehicles due to the low energy density of pure electric vehicles power batteries and the short life of batteries, and the range extender can solve this problem in terms of overall power performance, fuel consumption and NVH (noise, vibration and harshness) performance [1].

Extended-range Electric Vehicle (ReEV) belongs to series hybrid electric vehicle. The ReEV can realize pure electric and extended range operation mode. We need to consider the difference of power requirement between range extender and internal combustion engine(ICE) of Conventional fuel vehicle $[2,3]$ that should be fully considered in the early stage of range extender system development and system $\mathrm{NVH}$ target setting and also need to consider the NVH performance of ReEV with range extender under different modes [4-6]. NVH performance always different of operation mode of ReEV, Pure electric mode are always quieter than mode powered by Range extender, specifically, the transition from the EV mode to Range extender mode can cause significant NVH issues [7-10].

\section{The control strategy of the range extender}

The general control strategy of the range extender includes: 1) single operating point; 2) multi operating points; 3 ) power following vehicle demand, the main pros and cons of control strategy is listed in Table 1.

During the matching process of the range extender, it is necessary to consider a variety of operation conditions of the range extender, focusing on the start and stop of the in first operating point $[9,10]$, and the effects of different transition rate and mode between the operating points of the range extender. On this basis, it is necessary to test vibration and noise level in the vehicle under the increase the speed and load of the range extender, according to the test results, a reasonable frequency layout is carried out to achieve the vehicle NVH performance [11-13].

In order to study the influence of the above control strategies on NVH performance, we have carried out objective tests. The main measurement points include: the vibration measurement point of the active side of the right mount of the range extender, the noise measurement point of the right ear of the driver, and the vibration measurement point of the seat rail. Among them, the 
measurement point of the right mount active side of the range extender mainly observes the change of the vibration of the range extender itself, and the other two measurement points in the vehicle are objectively felt by the driver.

During the matching process of the range extender, it is necessary to consider a variety of operation conditions of the range extender, focusing on the start and stop of the in first operating point, and the effects of different transition rate and mode between the operating points of the range extender. On this basis, it is necessary to test vibration and noise level in the vehicle under the increase the speed and load of the range extender, according to the test results, a reasonable frequency layout is carried out to achieve the best vehicle NVH performance.

In order to study the influence of the above control strategies on NVH performance, we have carried out objective tests. The main measurement points include: the vibration measurement point of the active side of the right mount of the range extender, the noise measurement point of the right ear of the driver, and the vibration measurement point of the seat rail. Among them, the measurement point of the right mount active side of the range extender mainly observes the change of the vibration of the range extender itself, and the other two measurement points in the vehicle are objectively felt by the driver.

Table 1. The main pros and cons of control strategy

\begin{tabular}{|c|c|c|c|}
\hline Control strategy & $\begin{array}{c}\text { Fuel consumption and } \\
\text { driving range }\end{array}$ & $\begin{array}{c}\text { Complex of control } \\
\text { strategy }\end{array}$ & $\begin{array}{c}\text { Nvh } \\
\text { performance }\end{array}$ \\
\hline Single operating point & $\odot \odot \odot$ & $\oplus \odot \odot$ & $\odot$ \\
\hline Multi operating points & $\odot \odot$ & $\odot \odot$ & $\odot \odot$ \\
\hline $\begin{array}{c}\text { Power following vehicle } \\
\text { demand }\end{array}$ & $\odot$ & $\odot$ & $\odot \odot \odot$ \\
\hline
\end{tabular}

\subsection{First operating point selected}

Before the operation of range extender, the vehicle runs in pure electric mode, and the NVH performance level of the vehicle is basically the same as that of pure electric vehicles. The starting process of the range extender will inevitably cause the increase in the vibration and noise in the vehicle, which is different from the engine start and stop of the traditional internal combustion engine, the main differences are: 1) The first operating point of the range extender is often higher than the idle speed of the conventional fuel vehicle engine, and need to provide additional external output power; 2) The ignition speed of the range extender is higher than that of the traditional internal combustion engine, this is because the start of the range extender is often dragged by the generator, and the generator has a larger power and torque than the starter. Therefore, the range extender start process can quickly pass through the resonance area of the range extender mount system to reach the isolation area. In this article, we mainly discuss the impact of the first operating point of the range extender on the NVH performance of the vehicle.

The first working point selected after the range extender starts is mainly based on the vehicle's minimum power and fuel economy requirements. At present, the initial speed of the prototype vehicle is $1200 \mathrm{rpm}$ according to the demand, and the other speed points $(1400 \mathrm{rpm} / 1800 \mathrm{rpm} / 2400 \mathrm{rpm})$ are designed mainly for evaluate the effect of different speed points on NVH performance.

The vibration of the seat rail is basically equivalent at operating points of $1400 \mathrm{rpm} / 1800 \mathrm{rpm} / 2400 \mathrm{rpm}$. When the operating point is $2400 \mathrm{rpm}$, there is a significant peak after the startup is completed.

\subsection{Transition mode between different operating points}

The transition mode between different operating points of the range extender will affect the noise and vibration in the vehicle. The specific transition mode is shown in Fig. 3, which mainly includes three ways: 1) The speed and power increase simultaneously; 2) The speed remains 
unchanged first, the power is increased, and then the speed is increased; 3) The power is kept unchanged, the speed is increased, and then the power is increased.

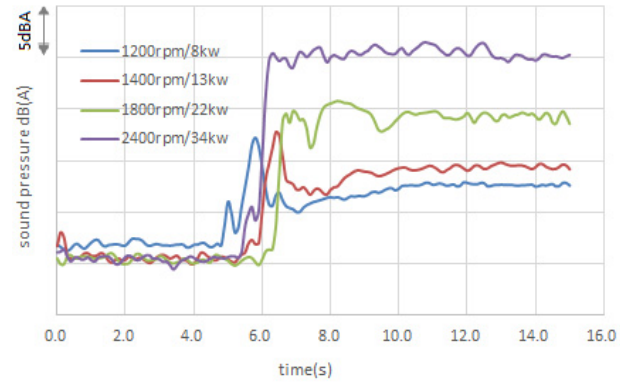

Fig. 1. Sound pressure of different operation points

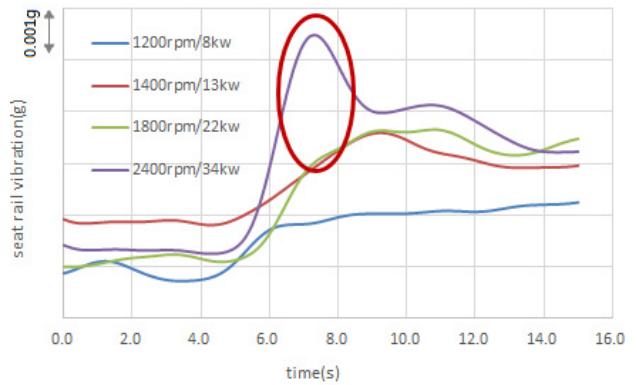

Fig. 2. Seat rail vibration of different operation points

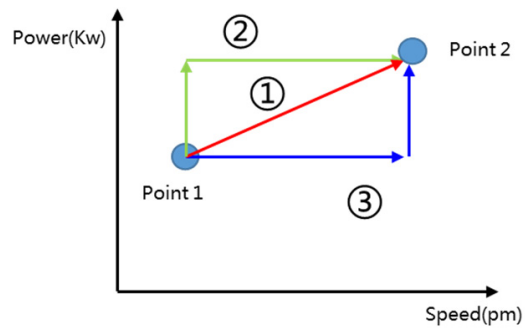

Fig. 3. Different transition mode of operating points

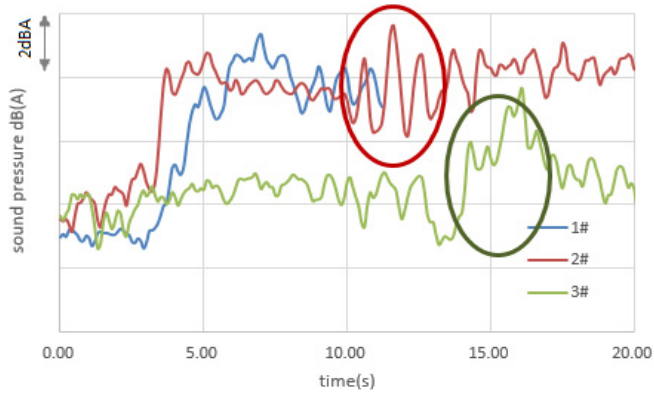

Fig. 4. Sound pressure of different transition mode

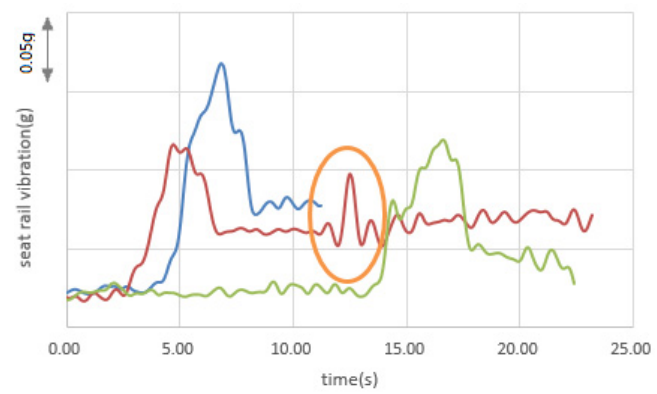

Fig. 5. Seat rail vibration of different transition mode

These three modes of transition tests were performed on a engineering prototype vehicle. The test results are shown in Figs. 3-5. When mode 1 is used, the vibration and noise will reach the maximum value after the completion of transition. When mode 2 is used, the vibration and noise will have secondary peak value, the sound pressure level in the vehicle is basically the same as that in mode 1, and the vibration of seat rail level in the vehicle is lower than that in mode 1 . When mode 3 is adopted, there is no obvious secondary peak in the whole transition process, the vibration and noise peak at the maximum power point, and the overall vibration and noise are lower than mode 1.Among the three modes, mode $3 \mathrm{NVH}$ performances better than mode 1 and mode 2.

\subsection{Transition rate between different operating points}

The transition rate between different operating points of the range extender will also affect the noise and vibration in the vehicle. The test results of different transition rates are shown in Fig. 6-7, where the initial speed is $1800 \mathrm{rpm}$, the target speed is $2400 \mathrm{rpm}$, the transition rate is 
$100 \mathrm{rpm} / \mathrm{s}, 200 \mathrm{rpm} / \mathrm{s}, 300 \mathrm{rpm} / \mathrm{s}$, and the corresponding transition time is $6 \mathrm{~S} / 3 \mathrm{~S} / 2 \mathrm{~S}$. When the transition rate is $200 \mathrm{rpm} / \mathrm{s}$ and $300 \mathrm{rpm} / \mathrm{s}$, there are obvious sound pressure peaks after the completion of the speed transition. The sound pressure level of $300 \mathrm{rpm} / \mathrm{s}$ is still higher than $100 \mathrm{rpm} / \mathrm{s}$ and $200 \mathrm{rpm} / \mathrm{s}$ in the following time, and $100 \mathrm{rpm} / \mathrm{s}$ has a good level, but correspondingly, the transition time is longer, which may affect the subjective feeling of driving.

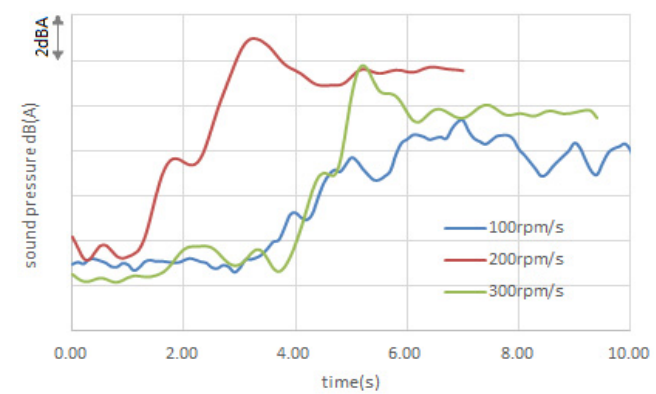

Fig. 6. Sound pressure of different transition rate

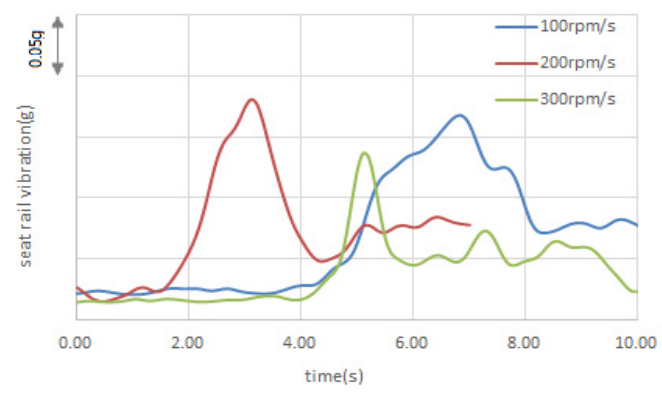

Fig. 7. Seat rail vibration of different transition rate

The vibration of the seat rail in the vehicle has the optimal vibration value at $300 \mathrm{rpm} / \mathrm{s}$. Under the two operating conditions of transition rate of $100 \mathrm{rpm} / \mathrm{s}$ and $200 \mathrm{rpm} / \mathrm{s}$, the peak vibration value is significantly higher than $300 \mathrm{rpm} / \mathrm{s}$, and the time span is $3 \mathrm{~s}$ and $2 \mathrm{~s}$.

\subsection{Confirmation of the operating points}

In the engineering prototype vehicle stage, the optimization and confirmation of the operating point of the range extender can quickly identify the NVH problem in the vehicle state, and ensure the frequency avoidance between the ignition order frequency of the range extender and the frequency of key components of the vehicle body, such as subframe, steering wheel, body panels, etc. The vibration and noise test results of the range extender operate under different loads and speeds are shown in Figs. 8-9. Among them, purple refers to the power line of $20 \mathrm{~kW}$ of the distance increaser, black refers to the power line of $30 \mathrm{~kW}$ of the distance increaser, and gray refers to the power line of $40 \mathrm{~kW}$ of the distance increase.

From the test data, the sound pressure of the right ear of the driver has peaks in the two speed ranges, 1) 2200-2400 rpm, 2) above $3000 \mathrm{rpm}$, and the vibration of the seat rail has a peak around $1400 \mathrm{rpm}$, and vibration problems also exist at $1200 \mathrm{rpm}$ under $80 \%$ and $90 \%$ load. Therefore, from the perspective of NVH control of the vehicle, it is recommended that 1) the speed of the range extender need to avoid 1300-1500 rpm, 2000-2450 rpm, and the maximum operating speed of the range extender is required to be less than $2800 \mathrm{rpm}$; 2) When the range extender load is above $80 \%$, the range extender speed should also avoid $1100 \mathrm{rpm}-1200 \mathrm{rpm}$.

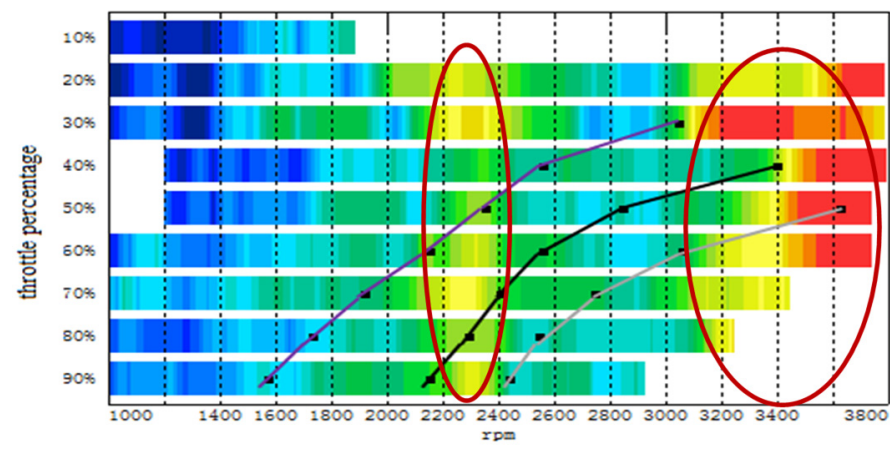

Fig. 8. Sound pressure of different throttle percentage 


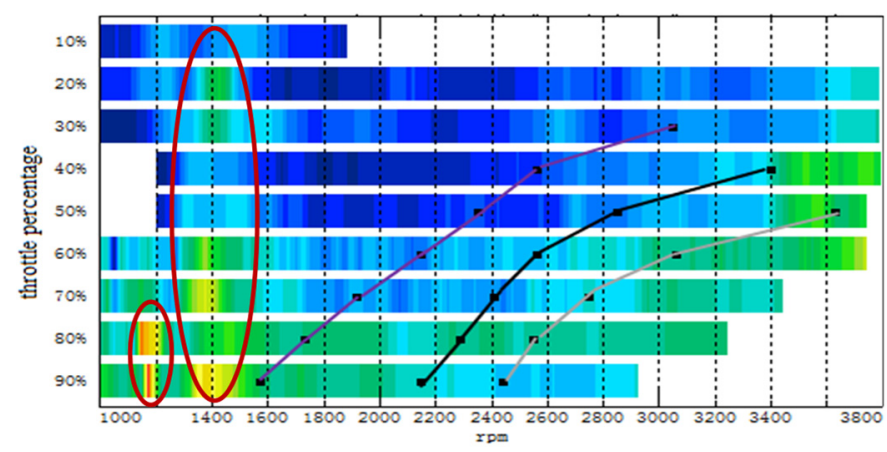

Fig. 9. Seat rail vibration of different throttle percentage

\section{NVH verification}

In the development process of a certain range extender vehicle, the key systems matching design and control strategy impact analysis were carried out in the early stage, and the range extender operating point was confirmed in the engineering prototype vehicle stage, which is conducive to improving the NVH performance level of the vehicle. The actual test results of the developed prototype vehicle and the target vehicles are shown in Figs. 10-11.

In the range extender mode, in the cruise speeds conditions, compared with the competing vehicles, the overall sound pressure of the right ear of the driver is lower than $4 \mathrm{dbA}$. At $100 \mathrm{~km} / \mathrm{h}$, the sound pressure is $62 \mathrm{dBA}$. In the whole open throttle condition, the overall sound pressure of the right ear of the driver is lower than $2 \mathrm{dBA}$. At $120 \mathrm{~km} / \mathrm{h}$, the sound pressure in the car is $67 \mathrm{dBA}$, which has good NVH performance, and subjective evaluation of the vehicle vibration and noise during the operation of the range extender is acceptable.

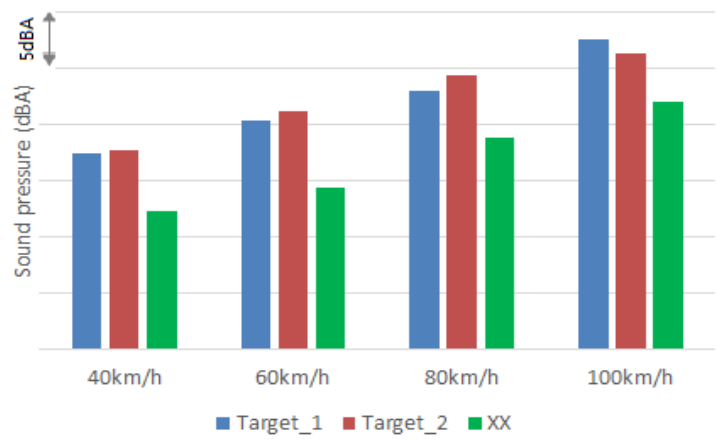

Fig. 10. Sound pressure in cruise speeds condition

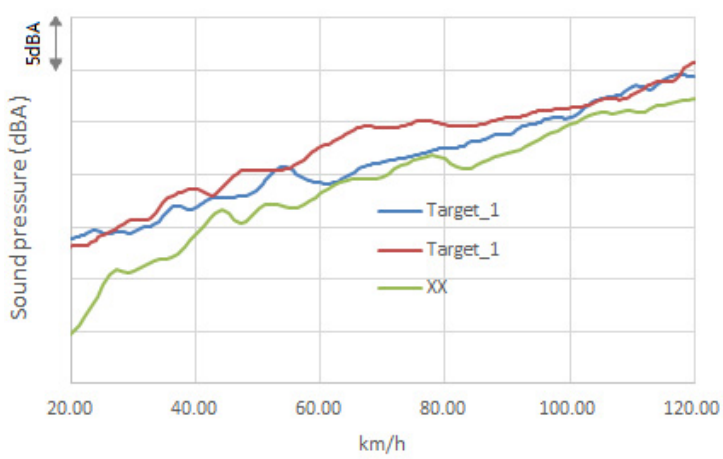

Fig. 11. Sound pressure in whole open throttle condition 


\section{Conclusions}

1) During the matching process of the range extender in the vehicle, various possible operating conditions of the range extender shall be considered, and the operating points shall be confirmed in the real vehicle, so as to ensure the reasonable planning of the ignition frequency of the operating point and the modal frequency of the vehicle body.

2) Through the relevant systems matching design and calibration control of the range extended range, the noise level in the range extender mode vehicle can meet the better NVH performance requirements.

\section{References}

[1] Friedl Hubert, Hubmann Christian, Teuschl Gerald Range extender technology for electric vehicles. 5th International Conference on Electric Vehicular Technology, 2018.

[2] Styler Alexander, Sauer Andreas, et al. Learned optimal control of a range extender in a series hybrid vehicle. 18th International Conference on Intelligent Transportation Systems, 2015.

[3] Heron Alex, Rinderknecht Frank Comparison of range extender technologies for battery electric vehicles. 8th International Conference and Exhibition on Ecological Vehicles and Renewable Energies, 2013.

[4] Govindswamy Kiran, Tomazic Dean The NVH behavior of internal combustion engines used in range extended electric vehicles. SAE Technical Paper 2013-01-2002, 2013.

[5] Trattner A., Pertl P., et al. Range extender concepts for 2025 with regard to small engine technologies. SAE Technical Paper 2011-32-0596, 2011.

[6] Rust Lfred, Graf Bernhard J. NVH of electric vehicles with range extender. SAE Technical Paper 2010-01-1404, 2010.

[7] Zhao Jing Bo, Han Bing Yuan, et al. Start-stop moment optimization of range extender and control strategy design for extended -range electric vehicle. 5th Asia Conference on Mechanical and Materials Engineering, 2017.

[8] Kiran G., Thomas W. Aspects of NVH integration in hybrid vehicles. SAE Technical Paper 2009-012085, 2009.

[9] Yi Rong Guo, et al. Subjective and objective evaluation of APU start-stop NVH for a range-extended electric vehicle. SAE Technical Paper 2015-01-0047, 2015.

[10] Pischinger Martin, Tomazic Dean, et al. A low NVH range-extender application with a small V-2 engine - based on a new vibration compensation system. SAE Technical Paper 2012-32-0081, 2012.

[11] Jeong Jongryeol, Lee Wonbin, et al. Control analysis and model validation for BMW i3 range extender. SAE Technical Paper 2017-01-1152, 2017.

[12] Waldner Jeff, Wise Jeremy, et al. Development and testing of an advanced extended range electric vehicle. SAE Technical Paper 2011-01-0913, 2011.

[13] Rogge Matthias, Rothgang Susanne, et al. Operating strategies for a range extender used in battery electric vehicles. Vehicle Power and Propulsion Conference, 2013. 